\title{
Persistent Spleen Enlargement in Sickle Cell Disease: An Unresolved Dilemma
}

\author{
Andreas Chiabi $^{{ }^{*}}$, Georges Kamsu $\mathrm{Moyo}^{2}$, Ines Ngone ${ }^{3}$, Daniel Armand T. Kago ${ }^{3}$, Annick \\ Tchouamou $^{3}$, Bolaji Obadeyi ${ }^{4}$ \\ ${ }^{l}$ Yaounde Gynaeco-Obstetric and Pediatric Hospital/Faculty of medicine and Biomedical Sciences, University \\ of Yaounde I, Cameroon \\ ${ }^{2}$ Faculty of medicine and Biomedical Sciences, University of Yaounde I, Cameroon \\ ${ }^{3}$ Yaounde Gynaeco-Obstetric and Pediatric Hospital, Cameroon \\ ${ }^{4}$ Healthlogics Limited, Lagos, Nigeria
}

*Corresponding Author: Andreas Chiabi, Yaounde Gynaeco-Obstetric and Pediatric Hospital / Faculty of medicine and Biomedical Sciences, University of Yaounde I, Cameroon, E-mail: andy_chiabi@yahoo.co.uk

\begin{abstract}
:
Sickle cell disease (SCD) is a hereditary blood disorder which affects mostly blacks of African descent. Spleen enlargement or splenomegaly is a common clinical manifestation in SCD, and normally develops progressively from about the age of 6 months, and is due mainly to repeated capturing and hemolysis of sickled red blood cells. The spleen then undergoes atrophy by the age of 6 years, as a result of vasoocclusion, ischemia and scarring. However, in a few cases, this splenomegaly may persist beyond 6 years, and may be responsible for frequent hemolytic episodes and acute splenic sequestration of red blood cells which can be fatal. The cause, role, consequences and management of a persistent spleen enlargement remains unclear, and is still an unresolved dilemma. This review discusses these various aspects in light of recent research on this issue. From this we conclude that, there is a wide array of clinical implications and therapeutic options, which have to be considered in the management of these patients to avert deadly complications.
\end{abstract}

Keywords: Sickle cell disease, children, persistent spleen enlargement

\section{EPIDEMIOLOGY}

Sickle cell disease (SCD) denotes a group of inherited genetic disorders characterized by abnormal structural hemoglobin synthesis, which is responsible for sickle-shaped red blood cells [1]. It is one of the most common recessive single-gene inherited disorders in humans, with more than 300,000 children born annually with SCD worldwide [2,3]. Three percent of such annual births occur in the USA and close to $75 \%$ in sub-Saharan Africa, where the greatest impacts of the disorder are reported [3, 4].

The highest prevalence of SCD in Africa has been recorded in countries such as Nigeria and Uganda, with incidences of $30 \%$ and 45\% respectively [3, 4]. Nevertheless, sickle cell patients may be found in almost all continents due to migration of populations [3]. In SCD, abnormally shaped and rigid red blood cells stick together, rupture in tiny blood vessels and are responsible for a wide range of clinical manifestations due to vaso-occlusive events and hemolysis $[1,5]$. Patients with SCD are thus exposed to acute crises such as osteo-articular pains, anemia, increased risks of infection and progressive tissue damage of organs including the spleen $[1,6]$. The spleen is the first organ affected by the complications of SCD, as the majority of affected children have spleen dysfunctions before 12 months of age [6,7].A considerable proportion of sickle cell patients, as many as $9 \%$, develop persistent splenomegaly which could be associated with a number of complications [8, 9]. Between 1999 and 2003, up to $4.5 \%$ of SCD admissions in the Al-Hassa region of Saudi Arabia comprised splenomegaly complications such as splenic sequestration and hypersplenism [8].

\subsection{Pathogenesis}

Progressive injury in the spleen start when transition of fetal to adult hemoglobin occur around the age of 6 months with decreasing 
levels of fetal hemoglobin (HbF) [7]. However, several pathological processes varying from acute to chronic events may be responsible for the persistence of splenomegaly in SCD [7]:

\subsubsection{Fibrocongestion}

The microcirculation of the spleen causes slow blood flow which favors deoxygenation and therefore increased sickling of red blood cells [7]. The less easily deformed and fragile red blood cells become sequestered in the micro vessels of the spleen, aided by over expression of adhesion molecules; all of which leads to vaso-occlusion and hemolysis $[10,11]$. This causes diffused congestion of the sinusoids and splenic cords which is responsible for splenic enlargement, as the process may occur repeatedly in most parts of the spleen [7]. Further contributive lesions described are those of infarctions characterized by focal or extensive calcifications, hemosiderine deposit and sclerosiderotic granules, known as Gandygamma bodies [8]. Perisplenitis comprising organized chronic inflammatory granulations in the pericapsular areas have also been described [8]. Moreover, gross capsular coarseness and nodularity are thought to be responsible for a thick capsule [8].

\subsubsection{Hypersplenism}

Persistent splenomegaly is often associated with chronic hypersplenism which is characterized by continuous splenic retention of circulating erythrocyte mass thereby contributing to the preservation of a hyperactive voluminous spleen [7, 8]. Moreover, relapses of acute sequestration could equally be responsible for maintaining an enlarged spleen in sickle cell children beyond 6 years $[7,8]$.

\subsubsection{Infections}

In the tropics, infectious agents may further impact the size of the spleen, especially in malaria-endemic countries, where there is repeated immunologic responses towards persistent malarial antigens [12]. This is responsible for Hyperactive Malarial Splenomegaly (HMS) which is the most frequent cause of tropical splenomegaly [12]. Therefore, unrecognized Plasmodium falciparum in SCD may trigger acute hemolytic events and vaso-occlusive crisis with characteristic hypersplenism and acute or chronic spleen enlargement [12].

\subsubsection{Hemoglobin $F$}

Some particular SCD have equally been suspected for the maintenance of splenomegaly as they are associated with higher levels of $\mathrm{HbF}>20 \%$, which reduces recurrent infarctions, normally responsible for autosplenectomy and eventually spleen atrophy $[13,14,15]$. Therefore the presence of these SCD does not lead to splenic atrophy but rather sustained splenic enlargement. Such variants of SCD include $\beta$-thalassemia, Asian halotype $\beta^{\text {s }}$, coinherited $\alpha$-thalassemia and $\mathrm{HbSC}$, with incidences of persistent splenomegaly as high as 50 to $60 \%[14,16,17,18]$. Because of the reduced rate of sickling due to increased levels of fetal hemoglobin in such SCD, protective functions related to reduced crises were noted by some authors, pointing out that persistent splenomegaly may therefore be specific to milder SCD $[8,14,19,20]$.

\subsection{Pathophysiology}

Splenomegaly in SCD may combine with hyposplenism or hypersplenism [7, 8]. However, the sequence of events in splenic injury remains hypothetical, and may only be described separately [7].

As far as hyposplenism is concerned, two mutually non-exclusive mechanisms have been proposed to explain its pathogenesis in SCD [7]. Firstly, it may result from red pulp congestion which causes hemodynamic diversion of blood from closed pathways, thus shunting filtration beds. Secondly, hyposplenism may be due to limited erythrophagocytosis and incomplete clearance of harmful antigens, occurring as a result of spleen macrophages being overwhelmed by sickled red blood cells [7]. Blood cells, pathogens and procoagulant particles escaping from a defective spleen may associate with hemolysis induced Nitrogen Monoxide (NO) synthesis to activate endothelial dysfunction leading to increased vaso-occlusive crises and vascular complications $[7,21,22$, 23]. Hyposplenism also predisposes sickle cell patients to recurrent infections. Before the adoption of antibiotic prophylaxis with penicillin and immunization with conjugated vaccines, invasive infections with pneumococcus, H. Influenza, or meningococcus could occur in as many as 15 to $20 \%$ of sickle cell patients $[24,25]$. Some years ago, other pathogens such as Salmonella were found as prevalent in sickle cell patients' infections, and may similarly be considered, unless proven otherwise by culture $[24,25]$. 
On the other hand, hypersplenism corresponds to an enlarged overactive spleen which is responsible for premature capturing and destruction of blood cells. The various pathogenic mechanisms in hypersplenism involve splenic retention of blood cells, phagocytosis and autoimmunity [26]. Hypersplenism may occur spontaneously or be triggered by some factors such as infection, inflammations, splenic congestion, hematological disorders including neoplasia, destruction of red blood cells or sequestration $[8,27,28]$. Acute splenic sequestration may be considered as a severe form of hypersplenism. Specific triggering factors for acute splenic sequestration are an increased rate of sickling, vaso-occlusive crises, fever and infections, with human parvovirus 19 mainly [7, 29]. Although the implication of human parvovirus virus B19 in the onset of acute splenic sequestration has been emphasized in the literature, its precise splenic pathogenicity in SCD is still to be elucidated. However, a prompting event to acute splenic sequestration is found in 50\% of cases and should be investigated [7].

\subsection{Manifestations}

The characteristic variation of the size of the spleen and the associated hematological disorders in sickle cell children have been of interest for clinicians and researchers over the years $[30,31]$.

\subsubsection{Persistent Splenomegaly with Hypersplenism}

When persistent splenomegaly is combined with hypersplenism, thereexists a continuous predisposition to acute splenic sequestration, infarction, abscess and chronic hypersplenism $[32,33]$. Hypersplenism clinically denotes the association of splenomegaly with any of hematologic anomalies such as anemia, leucopenia or thrombocytopenia, and a compensation bone marrow hyperplasia over an extended period, which improves after splenectomy [7]. Given the characteristic low hemoglobin level and the usual leukocytosis in SCD, the reference hematological signs considered in practice are thrombocytopenia and "unusually normal" leucocyte count [7]. Some authors described repercussions of hypersplenism in children such as reduced growth rate and bone marrow hyperplasia [7]. Chronic hypersplenism and acute splenic sequestration are more frequent, causing hematological disorders and may only have splenectomy as definite solution [34, 35]. An acute splenic sequestration may be the first life- threatening event in the sickle cell child [36]. It may clinically be defined as an acute splenomegaly with a rapidly decreasing hemoglobin level of at least $20 \mathrm{~g} / \mathrm{l}$ or $20 \%$ from baseline, and a normal increased reticulocyte count [27]. Acute splenic sequestration is generally characterized by pains, anemia, hypovolemic shock and death in case there is no appropriate intervention [7]. On the other hand, massive splenic infarction involving more than $50 \%$ of its size and splenic abscess are relatively rare [34]. They manifest clinically by an acute pain in the left hypochondrium which may be associated with fever in case of an abscess [34]. Massive infarction is described to be more common in SCD such as $\mathrm{HbSC}$, HbSE, $\mathrm{S} \beta^{+}$thalassemia [30]. In some cases, splenic infarction may predispose to an abscess, and the two may be mistaken for one another, though the diagnosis is made easier by either ultrasound or CT-scan [21, 33].

\subsubsection{Persistent Splenomegaly with Hyposplenism}

In cases where a persistent splenomegaly is associated with hyposplenism, there is progressive loss of function of the spleen, involving alterations of immunity, blood filtration and hematopoietic functions. Clinically, it may be characterized by recurrent infections in sickle cell children, and the presence of basophilic nuclei remnants in erythrocytes, known as Howell-Joly bodies (HJB) [7].

\subsection{Complications}

When persistent splenomegaly is combined with hyposplenism, some vascular complications such as stroke, pulmonary embolism, pulmonary arterial hypertension, and myocardial infarction may occur as a result of increased thrombosis due to vaso-occlusion [7, 22, 23]. Immunity tolerance to which the spleen contributes through trapping of some apoptotic and normal body cells may as well be disrupted by hyposplenism. Increased susceptibility to infections resulting from hyposplenism is frequent, especially before 2 years of age, when adaptive immunity depends on IgM opsonisation for $\mathrm{T}$-cell mediated protection against encapsulated bacteria [7]. Splenic abscesses though rare, may develop from invasive infections or sepsis [34].

In case where persistent splenomegaly is associated with hypersplenism, there is a sustained risk of acute splenic sequestration with up to $75 \%$ possibility of relapse [28]. 
Moreover, acute splenic sequestration is the first indication of splenectomy and the second cause of death after infections in SCD [34].

\subsection{Management}

The treatment of persistent spleen enlargement in SCD may depend essentially on the functional characteristics of the spleen, its associated complications and the age of the patient [7, 8]. Management could be conservative or radical depending on the severity of the case [34].

When persistent splenomegaly is associated with hyposplenism, there is a need to reduce the susceptibility to encapsulated bacterial infections. This is achieved by adequate immunization and antibiotic prophylaxis [37]. As far as immunization is concerned, the early administration of conjugated 13-valent pneumococcal vaccines (PCV) and 23-valent polysaccharide vaccines (PPV), together with Haemophilus influenza type $B$ and meningococcal conjugate vaccines is recommended [7, 8]. This has led to significant reduction of invasive infections due to pneumococcus, H. influenza, and meningococcus in SCD [27, 37, 38]. Concerning antibiotic prophylaxis, lifelong daily administration of penicillin $\mathrm{V}$ at 250 to $300 \mathrm{mg}$ twice daily or amoxicillin $250 \mathrm{mg}$ two times per day is recommended above 5 years of age and should be started as early as possible to cover up hyposplenism [7, 8, 39]. Macrolides could be used at adequate doses in case of allergy [39]. Malaria prevention within secticide-treated nets is equally recommended in SCD, especially in malaria endemic zones [40, 41].

In cases where persistent splenomegaly is associated with hypersplenism, with less frequent acute sequestration episodes, parental education to avoid triggering factors and early consultations could be done [42]. When crisis occur, careful fluid and/or blood transfusions are recommended, as they may help to release spleen trapped cells [7]. Prophylactic blood transfusion can be discussed so as to prevent life-threatening emergencies with shock or severe anemia [42]. Blood transfusions may be more indicated on a short term basis, and this has an additional advantage to avoid postsplenectomy infections [27]. Splenic embolization was proposed given the reluctance of some parents for repeated transfusions, unavailability of blood, allosensitization, blood borne infections and acute sequestration after transfusion. However, frequent complications make it an unsuitable line of management [43, 44, 45]. Hydroxyurea which is extensively used in the management of SCD has shown improvements of splenic functions, but there is no evidence of splenomegaly reversal [46]. Splenectomy in patients with hypersplenism seems beneficial as significant increase in hemoglobin, platelets, leucocytes and a decrease in the level of reticulocytes after splenectomy have been described [35]. Furthermore, splenectomy in sickle cell patients with hypersplenism reduces their transfusion requirements and the discomfort from mechanical pressure due to the enlarged spleen [34]. According to recent studies, hypersplenism appears to be the second cause of splenectomy in SCD after acute splenic sequestration [34].

In children with a history of splenic sequestration who present with massive infarction, abscesses or an acute sequestration crisis, splenectomy might be the best intervention given the possibility of future recurrences $[8,34]$. In practice, a major acute splenic sequestration crisis is a well-documented indication for splenectomy [35, 47, 48]. Moreover, splenectomy may equally be indicated if the child develops two minor attacks of acute splenic sequestration $[8,35]$. This is thought to prevent a recurrent risk of 40 to $50 \%$ and mortality rate reduction of about $20 \%$ in SCD $[49,50]$. Even though splenectomy seems to be the permanent solution to splenic complications in SCD, the main concerns may be about overwhelming post-splenectomy infections (OPSI) and the dilemma between partial and total splenectomy. In effect, there is no evidence of increased infections after splenectomy, especially beyond 2 years of age in immunized children compared to unimmunized infants $[7,50]$. Therefore, continuous vaccination against encapsulated bacteria and penicillin prophylaxis within 2-3 years following splenectomy is recommended, and patients educated to seek medical assistance at the earliest sign of infection [34]. On the other hand, splenectomy, if total, will prevent further sequestration and if partial, may reduce the recurrence of acute splenic sequestration crises [51]. Nevertheless, there is lack of evidence from trials to show that splenectomy improves survival and decreases morbidity in people with sickle cell disease [51]. Splenectomy in SCD may be contraindicated in a non-operable or unstable patient and in the absence of indications [32]. Partial splenectomy, 
because of possible residual immunity functions of a spleen remnant has been recommended in very young infants, but its applicability with regards to relatively older sicklers with persistent splenomegaly is not described [7]. Some researchers recommend laparoscopic splenectomy should prevail as much as possible over other forms of surgeries [32].

\section{CONCLUSION}

Spleen enlargement is a common sign in sickle cell children up to the age of 5 to 6 years, after which it is expected to undergo atrophy. However, the persistence of splenomegaly most often occurs in milder SCD, and is associated with functional impairments and sustained risk of recurrent acute sequestration crises. Splenectomy appears to be the most appropriate preventive and curative intervention as far as persistent splenomegaly and its complications in SCD are concerned.

\section{REFERENCES}

[1] Booth C, Inusa B, Obaro SK. Infection in sickle cell disease: a review. Int J Infect Dis. 2001 Jan; 14(1):e2-e12.

[2] Chakravorty S, Williams TN. Sickle cell disease: a neglectedchronic disease of increasing global health importance. Arch Dis Child.2015 January; 100(1):48-53.

[3] Piel FB, Tatem AJ, Huang Z, Gupta S, Williams TN, Weatherall DJ et al. Global migration and changing distribution of sickle cell hemoglobine: a quantitative study of temporal trends between 1960 and 2000. Lancet Global Health.2014 February; 2(2):e80-e89.

[4] Piel FB, Hay SI, Gupta S, Weatherall DJ, Williams TN. Global burden of sickle cell anemia in children under 5. 2010-2050: modelling based on demographics, excesss mortality and interventions. Plos Med. 2013; 10e1001484.

[5] Weatherall D, Hofman K, Rodgers G, Ruffi NJ, Hrynknow S. A case for developing north-south partnership for research in sickle cell disease. Blood. 2005; 105:921-3.

[6] Ebert EC, Nagar M, Hagspiel KD. Gastrointestinal and hepatic complications of sickle cell disease. Clin Gastroenterol Hepatol.2010; 8(6):483-489; quiz e470.

[7] Brousse V, Elie C, Benkerrou M, Odièvre MH, Lesprit E, Bernaudin F, et al. The spleen and sickle cell disease: the sick (led) spleen. $\mathrm{Br} \mathrm{J}$ Haematol. 2014 Jul; 166(2):165-76.

[8] Chopra R, Al-Mulhim AR, Al-Baharani AT. Fibro congestive splenomegaly in sickle cell disease: A distinct clinicopathological entity in east province of Saudi Arabia. Am J Hematol.2005; 79:180-186.

[9] Serjeant GR. Irreversibly sickled cells and splenomegaly in sickle-cell anemia. $\mathrm{Br} \mathrm{J}$ Haematol. 1970; 19:635-41.

[10] Wandersee NJ, Punzalan RC, Rettig MP, Kennedy MD, Pajewski NM, Sabina RL, et al. Erythrocyte adhesion is modified by alterations in cellular tonicity and volume. $\mathrm{Br} \mathrm{J}$ Haematol. 2005; 131:366-377.

[11] El Nemer, Gane P, Colin Y, Bony V, Rahuel C, Galacteros F, et al. The Lutheran blood group glycoproteins, the erythroid receptors for laminin, are adhesion molecules. J Biol Chem. 1998; 273: 16686-16693.

[12] De Franceschi L, Sada S, Andreoli A, Angheben A, Marocco S, Bisoffi Z. Sickle cell disease and hyperreactive malarial splenomegaly (HMS) in young immigrants from Africa. Blood. 2005; 106(13):4415-4417.

[13] Padmos MA, Roberts GT, Sackey K, Kulozik A, Bail S, Morris JS et al. Two different forms of homozygous sickle cell disease occur in Saudi Arabia. Br J Haematol.1991; 79:93-98.

[14] Wang WC. Sickle cell anemia and other sickling disorders. In: Greer JP, Foerster J, Lukens JN, Rodgers GM, Paraskevas F, Glader $\mathrm{B}$, editors. Wintrobe's clinical hematology. Philadelphia:Lippincott Williams \& Wilkins; 2004. P 1263-1312.

[15] Babiker MA, El-Hazmi MAF, Al Jabori AM, Obeid H, Bahakim HM. Splenic function in children with sickle cell disease. Two different patterns in Saudi Arabia. Scand J Haematol 1985; 35:191-193.

[16] Kar BC, Satapathy RK, Kulozik AE, kulozik M, Sirr S, Serjeant BE, Serjeant GR. Sickle cell disease in Orissa State, India. Lancet 1986; 2:1198-1201.

[17] Higgs DR, Aldridge BE, Lamb J, Clegg JB, Weather all DJ, Hayes RJ, et al. The interaction of alpha-thalassemia and homozygous sicklecell disease. N Engl J Med.1982; 306:14411446.

[18] Zimmerman SA, Ware RE. Palpable splenomegaly in children with haemoglobin SC disease: haematological and clinical manifestations. Clin Lab Haematol.2000; 22: 145-150.

[19] Serjeant GR. Sickle cell disease. Lancet 1997; 350:725-730.

[20] Mallouh AA, Salamah MM. Hypersplenism in homozygous sickle-cell disease. Ann Trop Paediatr 1985; 5(3):143-146.

[21] Di Sabatino A, Carsetti R, Corazza GR. Postsplenectomy and hyposplenic states. Lancet. 2011; 378, 86-97.

[22] Fontana V, Jy W, Ahn ER, Dudkiewicz P, Horstman LL, Duncan R, Ahn YS. Increased 
procoagulant cell-derived micro particles (CMP) in splenectomized patients with ITP. Thromb Res. 2008; 122: 599-603.

[23] Kato GJ, Hebbel RP, Steinberg MH, Gladwin MT. Vasculopathy in sickle cell disease: biology, pathophysiology, genetics, translational medicine, and new research directions. Am J Hematol. 2009; 84: 618-625.

[24] Barrett-Connor. Bacterial infection and sickle cell anemia. An analysis of 250 infections in 166 patients and a review of the literature. Medicine 1971; 50: 97-112.

[25] Ram S, Lewis LA, Rice PA. Infections of people with complement deficiencies and patients who have undergone splenectomy. Clin Microbiol Rev. 2010; 23: 740-780.

[26] Yunfu LV, Wan Yee Lau, Yejuan Li, Jie Deng, Xiaoyu Han, Xiaoguang Gang et al. Hypersplenism: history and current status. Exp Ther Med. 2016; 12(4): 2377-2382.

[27] Topley JM, Rogers DW, Stevens MC, Serjeant GR. Acute splenic sequestration and hypersplenism in the first five years in homozygous sickle cell disease. Arch Dis. 1981 56, 765-769.

[28] Al Awamy B, Wilson WA, Pearson HA. Splenic function in sickle cell disease in Eastern Province of Saudi Arabia. J Pediatr 1984; 104:714-717.

[29] Mallouh AA, Qudah A. Acute splenic sequestration together with a plastic crisis caused by human parvovirus B19 in patients with sickle cell disease. J Pediatr.1993; 122(4) 593-595.

[30] R. Janet Watson MD, Hebert C, Lichtman MD, Henry D, Shapiro MD. Splenomegaly in Sickle Cell Anemia. Am J Med.1956; 20(2):196-206.

[31] Brown AK, Sleeper LA, Miller ST, Pegelow CH, Gill FM, Waclawiw MA. Reference values and hematologic changes from birth to 5 years in patients with sickle cell disease. Cooperative Study of Sickle Cell Disease. Arch Pediatr Adolesc Med. 1994; 148:796-804.

[32] Al-Salem AH, Qaisaruddin S. NasserallahZ, Al-Sabbous I, Al-Jama A. Splenectomy in patients with sickle cell disease. Am J Surg 1996; 171:254- 258.

[33] Wright JG, Hambleton IR, Thomas PW, Duncan ND, Venugopal S, Serjeant GR. Postsplenectomy course in homozygous sickle cell disease. J Pediatr 1999; 134(3):304-309.

[34] Ahmed H. Al-Salem. Splenic Complications of Sickle Cell Anemia and the role of splenectomy. ISRN Hematol. 2011; 2011: 864257.

[35] Al-Salem A H. Indications and complications of splenectomy for children with sickle cell disease. J Pediatr Surg.2006; 41(11):19091915, 2006.
[36] Airede A I. Acute splenic sequestration in a five-week-old infant with sickle cell disease. Journal of Pediatrics. 1992; 120(1):160.

[37] Ammann A J, Addiego J, Wara DW, Lubin B, Smith WB, Mentzer WC. Polyvalent pneumococcal-polysaccharide immunization of patients with sickle-cell anemia and patients with splenectomy. N Engl J Med. 1977; 297: 897-900.

[38] Payne AB, Link-Gelles R, Azonobi I, Hooper WC, Beall BW, Jorgensen JH, Juni B, Moore $\mathrm{M}$ et al. Invasive pneumococcal disease among children with and without sickle cell disease in the United States, 1998-2009. Pediatr Infect Dis. 2013; 32: 1308-1312.

[39] Salvadori MI, Price VE. Preventing and treating infections in children with asplenia or hyposplenia. Pediatr Child Health. 2014; 19(5): 271-274.

[40] McAuley CF, Webb C, Makani J, Macharia A, Uyoga S, Opi DH, Ndila C, Ngatia A, Scott JA, Marsh K, Williams TN. High mortality from Plasmodium falciparum malaria in children living with sickle cell anemia on the coast of Kenya. Blood. 2010; 116:1663-1668.

[41] Komba A N, Makani J, Sadarangani M, AjalaAgbo T, Berkley JA, Newton CR, Marsh K et al. Malaria as a cause of morbidity and mortality in children with homozygous sickle cell disease on the coast of Kenya. Clin Infect Dis. 2009; 49:216-222.

[42] Serjeant GR. The spleen in sickle cell disease. In: The Complete Spleen: A Handbook of Structure, Function, and Clinical Disorders. edited by A.J. Bowdler. 2001, pp. 251-257. Humana Press, Totowa, NJ.

[43] Alwmark A, Bengmark S, Gullstrand P, Joelsson B, Lunderquist A, Owman $\mathrm{T}$. Evaluation of splenic embolization in patients with portal hypertension and hypersplenism. Annals of Surgery. 1982; 196(5):518-524.

[44] Castaneda-Zuniga WR, Hammerschmidt DE, Sanchez R, Amplatz K. Nonsurgical splenectomy. Am J Roentgenol. 1977; 129(5):805-811.

[45] Wholey MH, Chamorro HA, Rao G, Chapman W. Splenic infarction and spontaneous rupture of the spleen after therapeutic embolization. $\mathbf{J}$ Vasc Interv Radiol.1978; 1(4):249-253.

[46] Claster S, Vichinsky E. First report of reversal of organ dysfunction in sickle cell anemia by the use of hydroxyurea: splenic regeneration. Blood. 1996:88(6):1951-3.

[47] Al Salem AH, Qaisaruddin S, Nasserullah Z, Al Dabbous I, Abu Srair H, Al Jam'a A. Splenectomy and acute splenic sequestration crises in sickle cell disease. Pediatr Surg Int. 1996; 11(1):26-28. 
[48] Emond AM, Collis R, Darvill D. Acute splenic sequestration in homozygous sickle cell disease: natural history and management. J Pediatr.1985; 107(2)201-206.

[49] Mills ML. Life-threatening complications of sickle cell disease in children. J Am Med Assoc. 1985; 254(11):1487-1491.

[50] Lesher A P, Kalpatthi R, Glenn JB, Jackson
[51] SM, Hebra A. Outcome of splenectomy in children younger than 4 years with sickle cell disease. J Pediatr Surg. 2009; 44: 1134-1138.

[52] Owusu-Ofori S, Hirst C. Splenectomy versus conservative management for acute sequestration crises in people with sickle cell disease. Cochrane Database Systematic Review. 2013; 5, CD003425.

Citation: Andreas Chiabi, Georges Kamsu Moyo, Ines Ngone, Daniel Armand T. Kago, Annick Tchouamou, Bolaji Obadeyi. Persistent Spleen Enlargement in Sickle Cell Disease: An Unresolved Dilemma. ARC Journal of Pediatrics.2020; 6(1):8-14. doi:dx.doi.org/10.20431/2455-5711.0601003.

Copyright: (C) 2020 Authors. This is an open-access article distributed under the terms of the Creative Commons Attribution License, which permits unrestricted use, distribution, and reproduction in any medium, provided the original author and source are credited. 